ISSN 1823-626X

\title{
Journal of Fundamental Sciences
}

available online at http://jfs.ibnusina.utm.my

\section{A study on preparation and characterization of carbon doped $\mathrm{TiO}_{2}$ nanotubes}

\author{
Srimala Sreekantan ${ }^{1}$, Roshasnorlyza $\operatorname{Hazan}^{1}$, Zainovia Lockman ${ }^{1}$ and Ishak Mat ${ }^{2}$ \\ ${ }^{1}$ School of Materials and Mineral Resources Engineering, Universiti Sains Malaysia, 14300, Nibong Tebal, Pulau Pinang, Malaysia \\ ${ }^{2}$ Advance Medical and Dental Institute, Eureka Complex, Universiti Sains Malaysia, 11800, Pulau Pinang, Malaysia \\ Received 17 November 2009, Revised 4 April 2010, Accepted 13 April 2010, Available online 25 May 2010
}

\begin{abstract}
The present study is directed to clarify the influence of carbon doping on the degradation of methyl orange. $\mathrm{TiO}_{2}$ nanotubes were prepared by anodizing titanium foils in a two electrode configuration bath with titanium foil as the anode and platinum as the counter electrode. The electrochemical bath consists of $1 \mathrm{M} \mathrm{Na}_{2} \mathrm{SO}_{4}$ with $0.7 \mathrm{~g}$ ammonium fluoride, $\mathrm{NH}_{4} \mathrm{~F}$. The nanotubes obtained were further doped with carbon via in-situ and ex-situ method. Incorporation of carbon on $\mathrm{TiO}_{2}$ via in-situ method is accomplished during the anodization process by introducing oxalic acid into electrolyte while the ex-situ doping involves carbon incorporation into pre-fabricated $\mathrm{TiO}_{2}$ nanotube via flame annealing using carbon blackN330. Characterization such as Scanning Electron Microscope (SEM), Energy Dispersive X-ray Analysis (EDX), and X-Ray Diffraction (XRD) are used to determine the surface morphology, composition of dopants, and phases exists. Well ordered nanotube with good adherence and smooth surface was obtained for both methods. When the oxide was annealed, X-ray diffraction analysis revealed the presence of anatase and rutile phase. The photocatalytic properties of the pure $\mathrm{TiO}_{2}$ and carbon doped $\mathrm{TiO}_{2}$ were tested for methyl orange degradation and the result indicated that the in-situ doped $\mathrm{TiO}{ }_{2}$ has much better degradation than the ex-situ and pure $\mathrm{TiO}_{2}$. The percentage of methyl orange degradation for in-situ was $20 \%$ and $41 \%$ higher than ex-situ doped $\mathrm{TiO}$ and pure $\mathrm{TiO}_{2}$, respectively.
\end{abstract}

| $\mathrm{TiO}_{2}$ | Nanotube | Anodization | Carbon doping | Photodegradation |

(B) 2010 Ibnu Sina Institute. All rights reserved. http://dx.doi.org/10.11113/mjfas.v6n1.167

\section{INTRODUCTION}

Among the new materials being developed for photocatalytic activity, n-type semiconducting $\mathrm{TiO}_{2}$ remains as one of the most promising materials because of its high efficiency, low cost, chemical inertness, ecofriendly nature and photostability $[1,2]$. Because of these great properties, $\mathrm{TiO}_{2}$ would be the best candidate to be used for much application such as photocatalyst [3], impant materials [4], hydrogen sensing [5], solar cell [6] and many more. When $\mathrm{TiO}_{2}$ is exposed to UV light, it could be used to convert photons into chemical or electrical energy by generating electron and holes. The electron and holes then react with surface species to produce highly oxidizing species which is capable to convert pollutants to nontoxic or less harmful substance. However, the widespread use of $\mathrm{TiO}_{2}$ is hindered by its low utilization of solar energy in the visible region (about 3-5\%) because of the wide band gap. Efficient use of solar radiation requires extending the photoresponse of $\mathrm{TiO}_{2}$ to visible wavelengths. Therefore, many efforts were directed towards modifying the band gap of $\mathrm{TiO}_{2}$ and thus extending its photoresponse into the visible region by doping process [7-19]. Various transition metal cationic dopants have been studied [7-9] but it has been found to inhibit the photocatalytic activity of $\mathrm{TiO}_{2}$.

Corresponding author at: School of Materials and Mineral Resources Engineering Universiti Sains Malaysia, 14300, Nibong Tebal, Pulau Pinang, Malaysia E-mail addresses: srimala@eng.usm.my (Srimala Sreekantan)
This is because the doped $\mathrm{TiO}_{2}$ suffers from a thermal instability or an increase in the recombination centres of the charge carriers [10]. Therefore, many have suggested that smaller band gap might also be achieved by incorporating anionic dopants such as nitrogen [11-14], carbon [15 -17] and sulphur [18-20] for the extension of photocataytic activity into visible region. In particular, carbon-doped $\mathrm{TiO}_{2}$ was indicated as one of the best in terms of band gap narrowing. It is therefore our intention to study on band gap engineering of $\mathrm{TiO}_{2}$ by carbon doping. In our previous study, we observed that few parameters affect the production of $\mathrm{TiO}_{2}$ nanotubes [21-25].

Herein we report on two different methods for preparing the doped $\mathrm{TiO}_{2}$. The first one involves in-situ method whereby the carbon incorporation into titanium foil was accomplished while fabricating $\mathrm{TiO}_{2}$ nanotube whereas the second one is ex-situ doping which involves carbon incorporation directly on pre-fabricated $\mathrm{TiO}_{2}$ nanotubes. Both methods were done via anodization. The source of dopant was oxalic acid $\left(\mathrm{C}_{2} \mathrm{H}_{2} \mathrm{O}_{4}\right)$ for in-situ method and carbon black N330 for ex-situ method.

\section{EXPERIMENTAL}

Anodization was done in a standard two-electrode bath with titanium as the working electrode and platinum as the counter electrode. High purity titanium foils ( $99.6 \%$ purity) 
of thickness $0.2 \mathrm{~mm}$ that was used in this study were purchased from STREM Chemicals. Prior to anodization, Ti foils were degreased by sonicating in acetone for 15 minutes followed by rinsing in deionised water and then dried in nitrogen stream. After drying, the foil was cut into $1 \mathrm{~cm} \times 4 \mathrm{~cm}$ area and exposed to the electrolyte which consisted of $100 \mathrm{ml} 1 \mathrm{M} \mathrm{Na}_{2} \mathrm{SO}_{4}$ with $0.7 \mathrm{~g} \mathrm{NH}_{4} \mathrm{~F}$. The $\mathrm{pH}$ of the electrolyte was measured using a digital $\mathrm{pH}$ meter. $\mathrm{H}_{2} \mathrm{SO}_{4}$ was added to the solution to adjust the $\mathrm{pH}$. The electrochemical treatment consisted of a potential ramp from open-circuit to a fixed value of $20 \mathrm{~V}$. The sweep rate was kept constant at $1 \mathrm{~V} / \mathrm{min}$. The bath was kept at room temperature. For purposes of in-situ carbon doping, oxalic acid $\left(\mathrm{C}_{2} \mathrm{H}_{2} \mathrm{O}_{4}\right)$ was included in the anodization bath for 30 minutes. After the anodization was completed, the carbon doped $\mathrm{TiO}_{2}$ sample was annealed at $500{ }^{\circ} \mathrm{C}$ for 2 hours in an air atmosphere furnace. The condition is chosen based on our preliminary studies which indicate that increasing the annealing temperature to $300{ }^{\circ} \mathrm{C}$ shows the existence of vaguely anatase peak and for $500{ }^{\circ} \mathrm{C}$ induce the formation of anatase and rutile with better crystallinity $[21,26]$. It is anticipated that the formation of crystalline phase in carbon doped sample will lead to enhanced photodegradation activity.

As for ex-situ doping, prior to carbon incorporation, $\mathrm{TiO}_{2}$ nanotubes were fabricated via anodization in $\mathrm{Na}_{2} \mathrm{SO}_{4}$ with $0.7 \mathrm{~g} \mathrm{NH}_{4} \mathrm{~F}$ at $\mathrm{pH}$ of 4 for 30 minutes. The doping were done via flame annealing in a typical horizontal furnace with heating and cooling rates of $10{ }^{\circ} \mathrm{C} / \mathrm{min}$ and the source of dopant being used is carbon black N330. Flame annealing with carbon black were done at $500{ }^{\circ} \mathrm{C}$ for 2 hours in saturated argon gas.

The morphologies of the anodized titanium were characterized using a Field Emission Scanning Electron Microscope (FESEM SUPRA 35VP ZEISS) operating at working distances down to $1 \mathrm{~mm}$ and extended accelerating voltage range from $30 \mathrm{kV}$ down to $100 \mathrm{~V}$. The FESEM SUPRA 35VP ZEISS was capable of energy dispersive $\mathrm{X}$ ray spectroscopy (EDX). The crystal phases of the $\mathrm{TiO}_{2}$ nanotubes were studied by $\mathrm{X}$-ray diffraction using the Bruker D8 powder diffractometer operating in the reflection mode with $\mathrm{Cu} \mathrm{K \alpha}$ radiation $(40 \mathrm{KV}, 30 \mathrm{~mA})$ diffracted beam monochromator, using a step scan mode with the step size of $0.1^{\circ}$ in the range of $25-70^{\circ}$. The step time was of 3 $\mathrm{s}$, adequate to obtain a good signal-to-noise ratio in the main reflections of the $\mathrm{TiO}_{2}$ nanotube, $\left(\begin{array}{lll}1 & 0 & 1\end{array}\right)$ anatase $(2 \theta=25.3$ $\left.{ }^{\circ}\right)$ and $\left(\begin{array}{lll}1 & 0 & 1\end{array}\right)$ rutile $\left(2 \theta=36.1^{\circ}\right)$. The weight fractions of the anatase and rutile phases of nanotube subjected to various heat treatment were estimated from the relative intensities of the strongest peaks corresponding to anatase and rutile respective integrated XRD peak intensities using the equation (1) [27]:

$$
X_{A}=\left(1+1.26 \frac{I_{R}}{I_{A}}\right)^{-1}
$$

where $X_{a}$ is a weight fraction of anatase in powder, and $I_{A}$ and $I_{R}$ are the $X$-ray integrated intensities of the $\left(\begin{array}{lll}1 & 0 & 1\end{array}\right)$ reflection of anatase and ( $\left.\begin{array}{lll}1 & 0 & 1\end{array}\right)$ reflection of rutile, respectively.

The photocatalytic degradation studies was performed by dipping 7 pieces of $1 \mathrm{~cm}^{2}$ foils made up of carbon doped $\mathrm{TiO}_{2}$ nanotubes in $200 \mathrm{ml}$ of $50 \mathrm{ppm}$ methyl orange in selfconstructed photoreactor which consist of a quartz glass. The sample was then left in the reactor for about $30 \mathrm{~min}$ in dark environment to achieve the adsorption / desorption equilibrium. It was then photoirradiated at room temperature by using TUV $18 \mathrm{~W}$ UV-C Germicidal light. 5 $\mathrm{ml}$ solution was withdrawn for every 1 hour from the quartz tube to monitor the degradation of methyle orange after irradiation. The concentration of the degradated methyl orange was determined using $\mathrm{UV}-\mathrm{V}$ is spectrometer.

\section{RESULTS \& DISCUSSION}

\subsection{Effect of different $\mathrm{pH}$ on $\mathrm{TiO}_{2}$ nanotube formation}

For this set of experiment, $0.7 \mathrm{~g}$ of $\mathrm{NH}_{4} \mathrm{~F}$ in $100 \mathrm{ml}$, $1 \mathrm{M} \mathrm{Na}_{2} \mathrm{SO}_{4}$ was used for anodization but the $\mathrm{pH}$ of the solution was altered from 3,4 , and 5 using $\mathrm{H}_{2} \mathrm{SO}_{4}$. The bulk electrolyte without the addition of $\mathrm{H}_{2} \mathrm{SO}_{4}$ has a $\mathrm{pH}$ of around 6. For all experiments, anodization was conducted at $20 \mathrm{~V}$ for 30 minutes. Different $\mathrm{pH}$ of the electrolyte leads to different surface structure of $\mathrm{TiO}_{2}$. Representative cross sections of the $\mathrm{TiO}_{2}$ formed at different $\mathrm{pH}$ 's are shown in Figure 1. For $\mathrm{pH} 3$, the sample seemed to be inadequate for formation of $\mathrm{TiO}_{2}$ oxide layer (Figure 1a). In some portion of the foil, a flake structure is observed and it was further confirmed with EDX. EDX analysis (the insert in Figure 1a) confirmed the absence of $\mathrm{TiO}_{2}$ oxide layer in both area $\mathrm{A}$ and $\mathrm{B}$. The Ti foil probably was severely etched, revealing the grain of the Ti.

Surface morphology of the $\mathrm{TiO}_{2}$ formed at $\mathrm{pH} 4$ and 5 are shown in Figure $1 \mathrm{~b}$ and $1 \mathrm{c}$. It clearly indicates that $\mathrm{pH}$ plays an important role for the formation of the nanotubes. It is also seen that the diameter of the tubes depends on the $\mathrm{pH}$ of the bath. For higher $\mathrm{pH}$, e.g. $\mathrm{pH}=4$ (Figure $1 \mathrm{~b}$ ), the average diameter of the tubes was approximately $80 \mathrm{~nm}$. When the $\mathrm{pH}$ of the bath was further increased to 5 , the diameter of the tubes was smaller i.e. $\sim 70 \mathrm{~nm}$ (Figure 1c). Further observation indicates that the thickness of the prepared nanotube influenced by $\mathrm{pH}$ of the bath. Higher $\mathrm{pH}$, i.e. $\mathrm{pH} 5$ leads to the formation thicker wall approximately $15 \mathrm{~nm}$ while lower $\mathrm{pH} 4$ results in thinner wall around 8 $\mathrm{nm}$. The electrolyte $\mathrm{pH}$ may adjust $\mathrm{TiO}_{2}$ dissolution rate at the pore bottom by localized acidification has been reported by Macak and co-worker [28]. Effects of migration and diffusion generate lower $\mathrm{pH}$ value at the pore bottom while higher $\mathrm{pH}$ value is obtained at the pore mouth. The smaller diameter and thicker wall of the nanotube with increasing $\mathrm{pH}$ is probably associated with chemical dissolubility of the electrolyte. At high $\mathrm{pH}$, the formation of $\left[\mathrm{TiF}_{6}\right]^{2-}$ complex is reduced and relatively result in weak chemical dissolubility. 
As a result, the diameter of the tube is small and the wall thickness is wide.
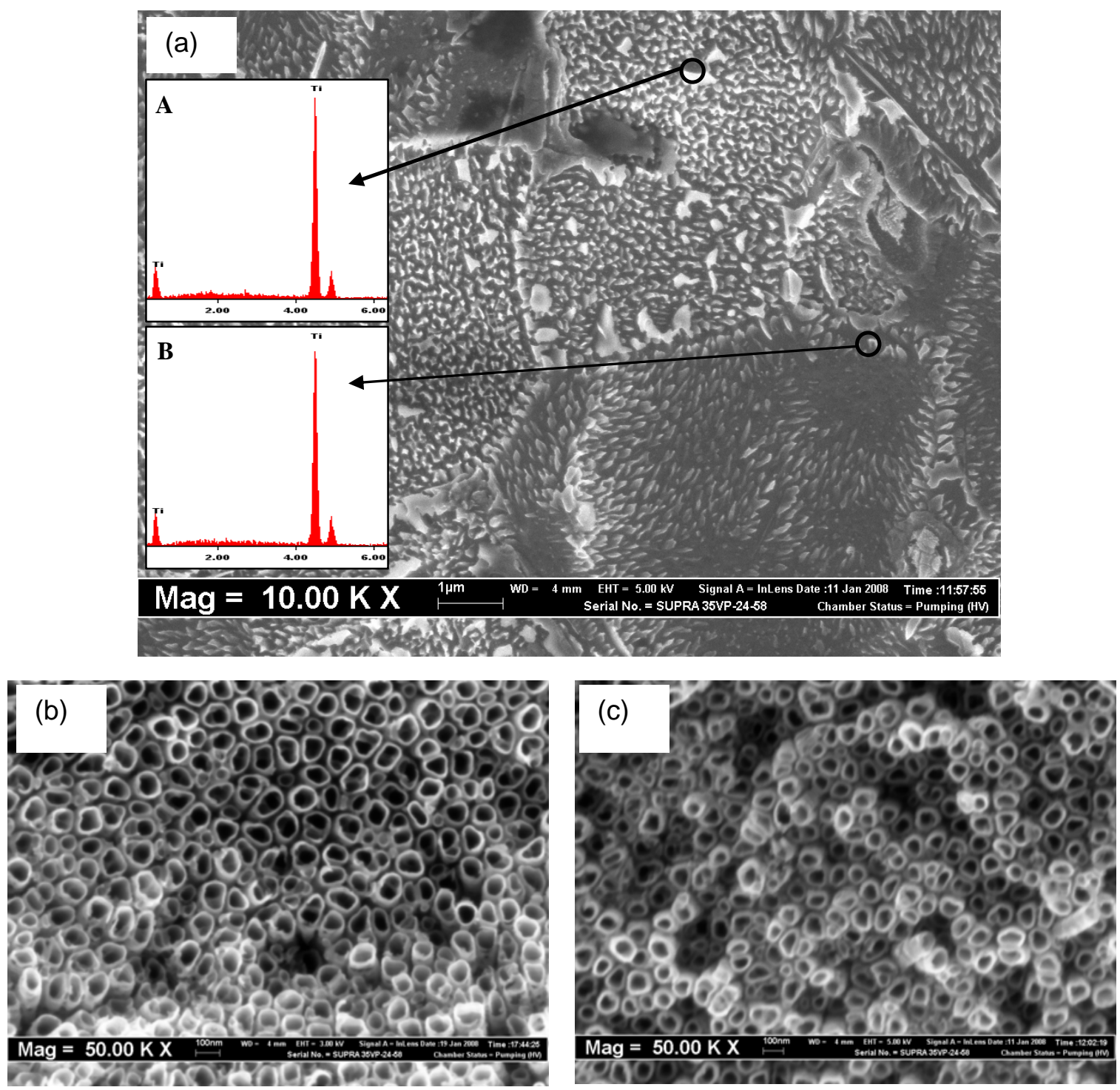

Figure 1: FESEM images of the $\mathrm{TiO}_{2}$ nanotubes obtained with different $\mathrm{pH}$ (a) $\mathrm{pH} 3$, (b) $\mathrm{pH} 4$ and (c) $\mathrm{pH} 5$

\subsection{Formation of carbon doped $\mathrm{TiO}_{2}$ nanotube via in-situ and ex-situ method}

From the first part of experiment, production of $\mathrm{TiO}_{2}$ nanotubes were found to be very well defined over the whole area of the foil (not shown) when the $\mathrm{pH}$ of the bath is 4 . Therefore, for the next set of experiment, the $\mathrm{pH}$ of the solution was fixed to 4 . Figure 2, shows FESEM image of a carbon doped $\mathrm{TiO}_{2}$ nanotubes with insets showing the length of the tubes. The tubes were obtained by in-situ doping technique using oxalic acid as a carbon source in 1 $\mathrm{M} \mathrm{Na} 2 \mathrm{SO}_{4}$ at room temperature for 30 minutes. $\mathrm{TiO}_{2}$ nanotubes with diameter of $80 \mathrm{~nm}$ and length of $1.3 \mu \mathrm{m}$ are obtained. The wall thickness was approximately $20 \mathrm{~nm}$.
EDX analysis was performed to clarify the incorporation of carbon on the prepared tubes. Representative EDX spectrum of the in-situ carbon doped $\mathrm{TiO}_{2}$ is shown in Figure 3. Twenty measurements were performed on each sample and average values were taken. The data demonstrate that the amount of doped carbon into $\mathrm{TiO}_{2}$ tubes was in the range of 6.3-6.5\%, hence indicating that the tubes possess uniform carbon content when anodized for 30 minutes. After the anodization was completed, the in-situ carbon doped $\mathrm{TiO}_{2}$ sample was annealed at $500{ }^{\circ} \mathrm{C}$ for 2 hours in an air atmosphere furnace. The morphology of the tubes after heat treatment was analyzed by FESEM and the result indicates no variation in the structure of the oxide 
(not shown) as compared to the structure formed before subjected to annealing process.

Figure 4 shows an illustrative FESEM image of $\mathrm{TiO}_{2}$ nanotube that have been doped with carbon black N330 via ex-situ method using flame annealing technique. Under this condition, the nanotubes have a length of $1.2 \mu \mathrm{m}$ with wall thickness of $20 \mathrm{~nm}$. The average nanotube diameter as calculated from the FESEM image was $80 \mathrm{~nm}$, similar to insitu doped sample. Representative EDX spectrum of the exsitu doped $\mathrm{TiO}_{2}$ is shown in Figure 5 and it was found that the average carbon content of the ex-situ doped $\mathrm{TiO}_{2}$ was slightly lower $(5.14 \%)$ as compared to in-situ doped $\mathrm{TiO}_{2}$. This is probably attributed to easier diffusion of oxalic acid due to its smaller size compared to carbon black.

\subsection{XRD analysis}

Figure 6 shows the crystal structure of pure $\mathrm{TiO}_{2}$ and carbon doped $\mathrm{TiO}_{2}$ nanotube which was produced after flame annealing. The result clearly shows the crystal

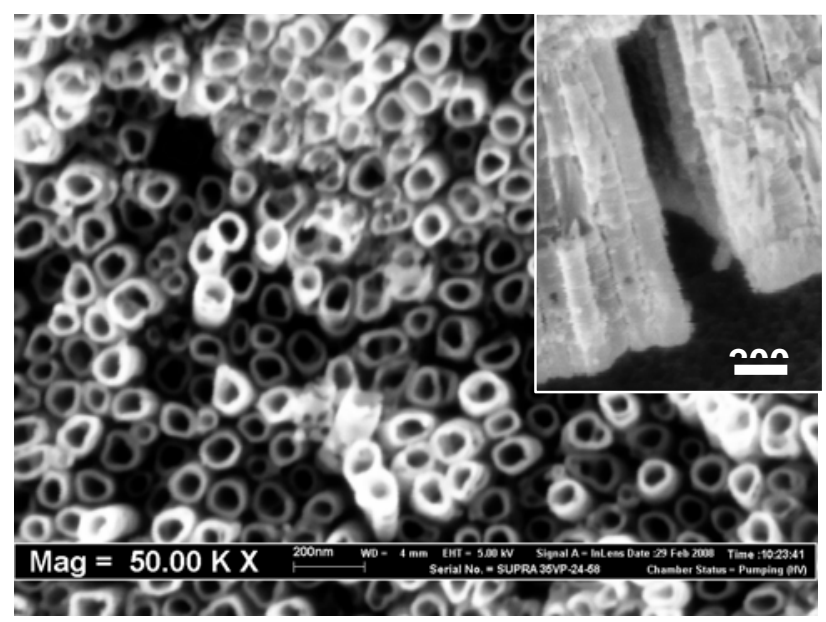

Figure 2: FESEM images of the carbon doped $\mathrm{TiO}_{2}$ nanotubes obtained via in-situ method

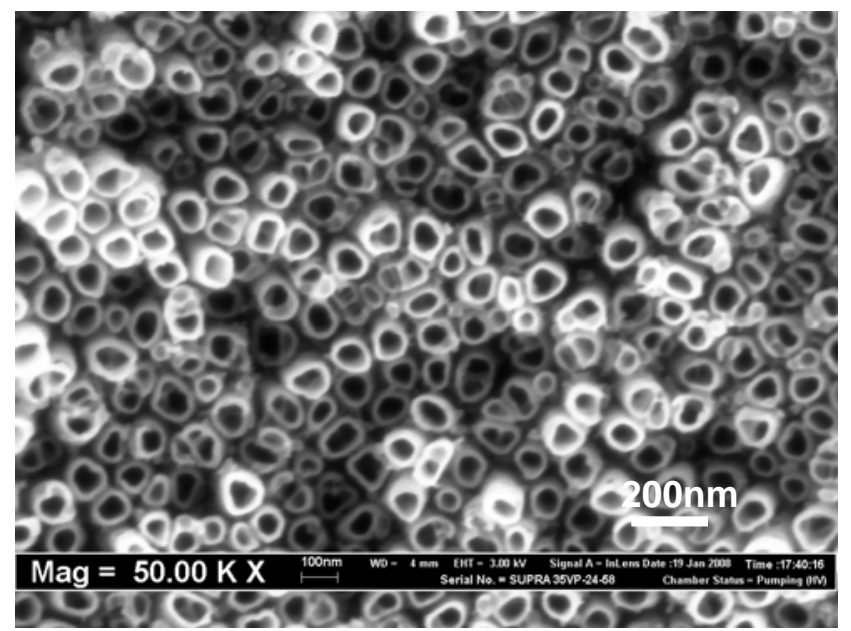

Figure 4: FESEM images of the carbon doped $\mathrm{TiO}_{2}$ nanotubes obtained via ex-situ method structure of $\mathrm{TiO}_{2}$ depends on the annealing treatment. XRD of the as-anodized sample (without dopant and annealing process) in Figure 6a indicated that the self-organized $\mathrm{TiO}_{2}$ nanotubes have amorphous structure as only Ti-peaks were shown. Habazaki has reported the formation of crystalline oxide in a film formed at $20 \mathrm{~V}$ [29]. In contrast to their finding, amorphous phase has been observed in this study and probably it is associated with the formation of localized crystalline oxides and not a continuous one throughout the oxide. However if the same sample heated at $500{ }^{\circ} \mathrm{C}$, it matches the reference pattern (ICDD card number 21-1272) of anatase at $2 \theta=25.28^{\circ}, 48.05^{\circ}, 53.89^{\circ}, 55.06^{\circ}$ and $62.69^{\circ}$ and rutile phase (ICDD card number 21-1274) at $36.08^{\circ}, 41.23^{\circ}$ and $54.32^{\circ}$, indicating transformation form amorphous structure to crystalline structure (Figure 6b). The weight fractions of the anatase and rutile phase were approximately $50.2 \%$ and $49.8 \%$, respectively. Similar phase structure was also found in in-situ carbon doped nanotube (Figure $6 \mathrm{c}$ ) with $62.8 \%$ of anatase and $37.2 \%$ rutile phases.

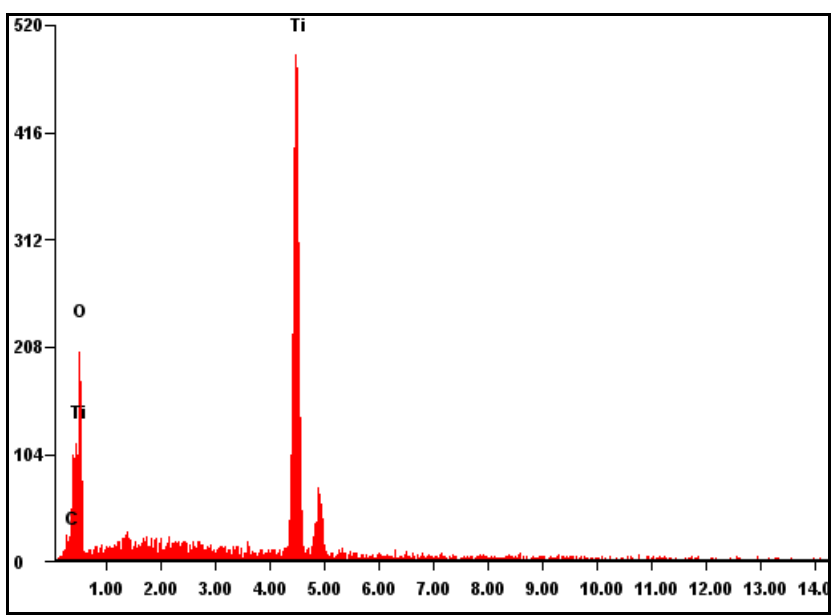

Figure 3: EDX spectrum of the carbon doped $\mathrm{TiO}_{2}$ nanotubes obtained via in-situ method

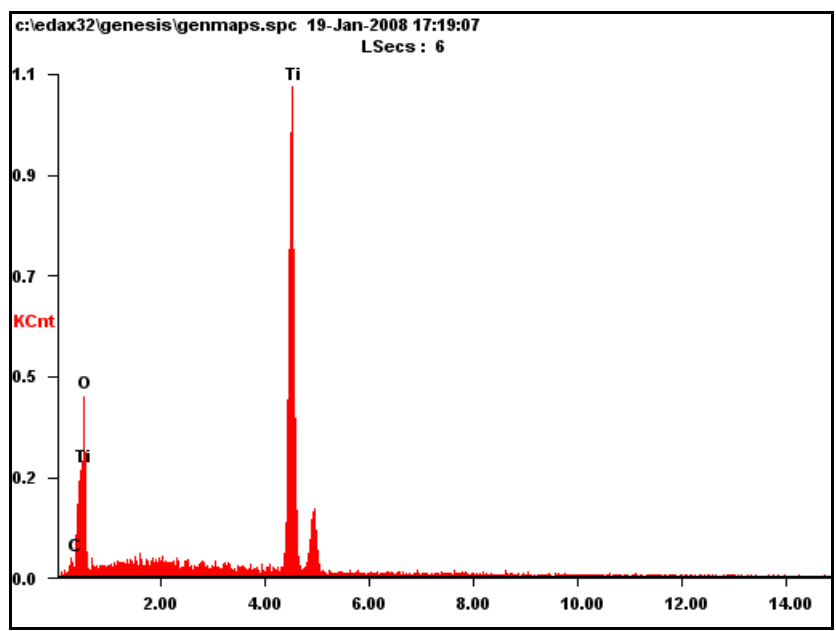

Figure 5: EDX spectrum of the carbon doped $\mathrm{TiO}_{2}$ nanotubes obtained via ex-situ method 


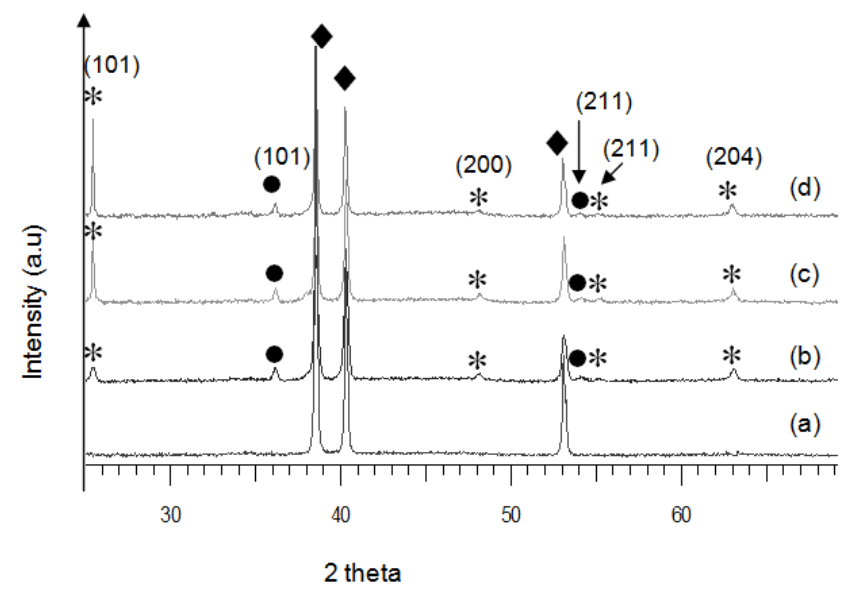

Figure 6: XRD pattern of (a) pure $\mathrm{TiO}_{2}$ and not annealed (b) pure $\mathrm{TiO}_{2}$ and annealed (c) in-situ carbon doped and annealed (d) ex-situ carbon doped and annealed [ $\bullet: \mathrm{Ti}, \bullet$ : rutile, $*$ : anatase]

Figure 6d shows the XRD pattern of the ex-situ doped $\mathrm{TiO}_{2}$ after flame annealed for 2 hours in carbon black. In addition to the observed prominent Ti peak, there are small peak at $2 \theta$ values of $25.28^{\circ}, 48.05^{\circ}, 53.89^{\circ}$, $55.06^{\circ}$ corresponding to the anatase phase (ICDD card number $21-1272$ ) and at $2 \theta$ values of $36.08^{\circ}, 41.23^{\circ}$ and $54.32^{\circ}$ corresponding to rutile (ICDD card number 211274) $\mathrm{TiO}_{2}$. The weight fractions of the anatase and rutile phases of doped nanotube were $66.7 \%$ and $33.3 \%$, respectively. It is worth to note that the weight fraction of anatase in carbon doped sample via in-situ and ex-situ is higher by $12 \%$ and $16 \%$ respectively as compared to the pure sample. The precious reason for the higher fraction of anatase in carbon doped sample are currently unclear and the subject of ongoing studies. However, based on our preliminary studies it is possible that oxygen rich atmospheric condition be an important factor in the formation of rutile phase (Table 1).

Table 1: Anatase to rutile ratio and the oxygen content during the annealing process for doped and undoped $\mathrm{TiO}_{2}$

\begin{tabular}{|l||c|c|c|}
\hline Samples & $\begin{array}{c}\text { Undoped } \mathrm{TiO}_{2} \text { after } \\
\text { annealing }\end{array}$ & In-situ Carbon doped & Ex-situ Carbon doped \\
\hline XRD Analysis & Anatase and Rutile & Anatase and Rutile & Anatase and Rutile \\
\hline \hline Ratio of anatase: rutile & $50.2: 49.8$ & $62.8: 37.2$ & $66.7: 33.3$ \\
\hline $\begin{array}{l}\text { Atmospheric condition } \\
\text { during annealing process }\end{array}$ & $\begin{array}{l}\text { Oxygen content are relatively } \\
\text { high as compared to insitu } \\
\text { and exsitu doped } \mathrm{TiO}_{2} \\
\text { because flame annealing was } \\
\text { done in air }\end{array}$ & $\begin{array}{l}\text { Probably carbon incoparation during } \\
\text { anodization have influence on the } \\
\text { atmospheric condition during annealing } \\
\text { process. Therefore oxygen content is } \\
\text { lower as compared to pure } \mathrm{TiO}_{2}\end{array}$ & $\begin{array}{l}\text { Oxygen content are the lowest } \\
\text { because flame annealing with } \\
\text { carbon black were done in } \\
\text { saturated argon gas }\end{array}$ \\
\hline
\end{tabular}

\subsection{Photocatalytic activity}

The photocatalytic activity of the pure $\mathrm{TiO}_{2}$ and doped (in-situ and ex-situ) $\mathrm{TiO}_{2}$ nanotube was evaluated by photodegrdation of methyl orange aqueous solution. Figure $7 \mathrm{a}$ and $7 \mathrm{~b}$ show the changes in absorption spectra of the methyl orange aqueous solution during its photodegradation using in-situ and ex-situ doped $\mathrm{TiO}_{2}$ nanotube, respectively. It could be seen the absorption peak gradually decreased with increasing UV irradiation time and this is attributed to the generation of electron and holes which is increasing with the irradiation time. After UV irradiation for 5 hours, the absorption peak of methyl orange aqueous solution for doped sample was weak. For comparison, the absorption spectrum of the pure $\mathrm{TiO}_{2}$ was also measured after 5 hours and it is shown in Figure $7 \mathrm{c}$. The experimental observation indicated that the colour of the methyl orange aqueous solution changed from dark orange to a pale orange or colourless one, depending on the pure $\mathrm{TiO}_{2}$ or doped $\mathrm{TiO}_{2}$. The colour changes actually indicating the degradation of methyl orange. To quantify the observed trends in Figure 8, the absorbance was converted to concentration with the following equation;

$$
\ln \left(\frac{C_{o}}{C_{t}}\right)=\ln \left(\frac{A_{o}}{A_{t}}\right)=k t
$$


Here $C_{o}$ is the initial dye concentration (at the end of sorption period), while $C_{t}$ is the actual dye concentration. $A_{o}$ is the initial absorption value while $A_{t}$ is the actual absorption value, $k$ is rate constant, $t$ is the time after UV irradiation.

Figure 8 shows the plots of methyl orange concentration versus irradiation time for in-situ and ex-situ doped sample. Illumination in the absence of photocatalyst did not result in the photodegradation (not shown). It was found that the in-situ doped $\mathrm{TiO}_{2}$ showed the greatest degradation whereby the concentration of methyl orange decreased rapidly by $69 \%$ after UV irradiation for 5 hours. As for ex-situ doped $\mathrm{TiO}_{2}$ nanotubes, the concentration decrease by $49 \%$. Pure $\mathrm{TiO}_{2}$ showed the lowest photodegradation whereby the concentration of methyl orange decreased by $28 \%$. Based on the results obtained, it seems that crystal structure is one of the important factors affecting the photocatalytic activity. According to Bakardjieva [17], $\mathrm{TiO}_{2}$ nanotubes with $70 \%$ anatase and 30 $\%$ rutile are the optimum ratio and showing great efficiency for photocatalytic activity. The similar observation can be seen in this work. In-situ and ex-situ carbon doped $\mathrm{TiO}_{2}$ with $62 \%$ and $66 \%$ of anatase, respectively showed better performance in the photodegradation of methyl orange as compared to pure $\mathrm{TiO}_{2}$ with $50 \%$ anatase. Less activity of pure $\mathrm{TiO}_{2}$ might be due to lack of anatase phase which can assist to reduce the rapid rate of recombination in rutile phase. Besides, pure $\mathrm{TiO}_{2}$ has no absorption above $400 \mathrm{~nm}$. However, the carbon doped $\mathrm{TiO}_{2}$ results in obvious absorption up to $700 \mathrm{~nm}$ [30]. This absorption features suggest that carbon doped $\mathrm{TiO}_{2}$ can be activated by visible light to enhance the electron transfer and thus improve the photodegradation of methyl orange.
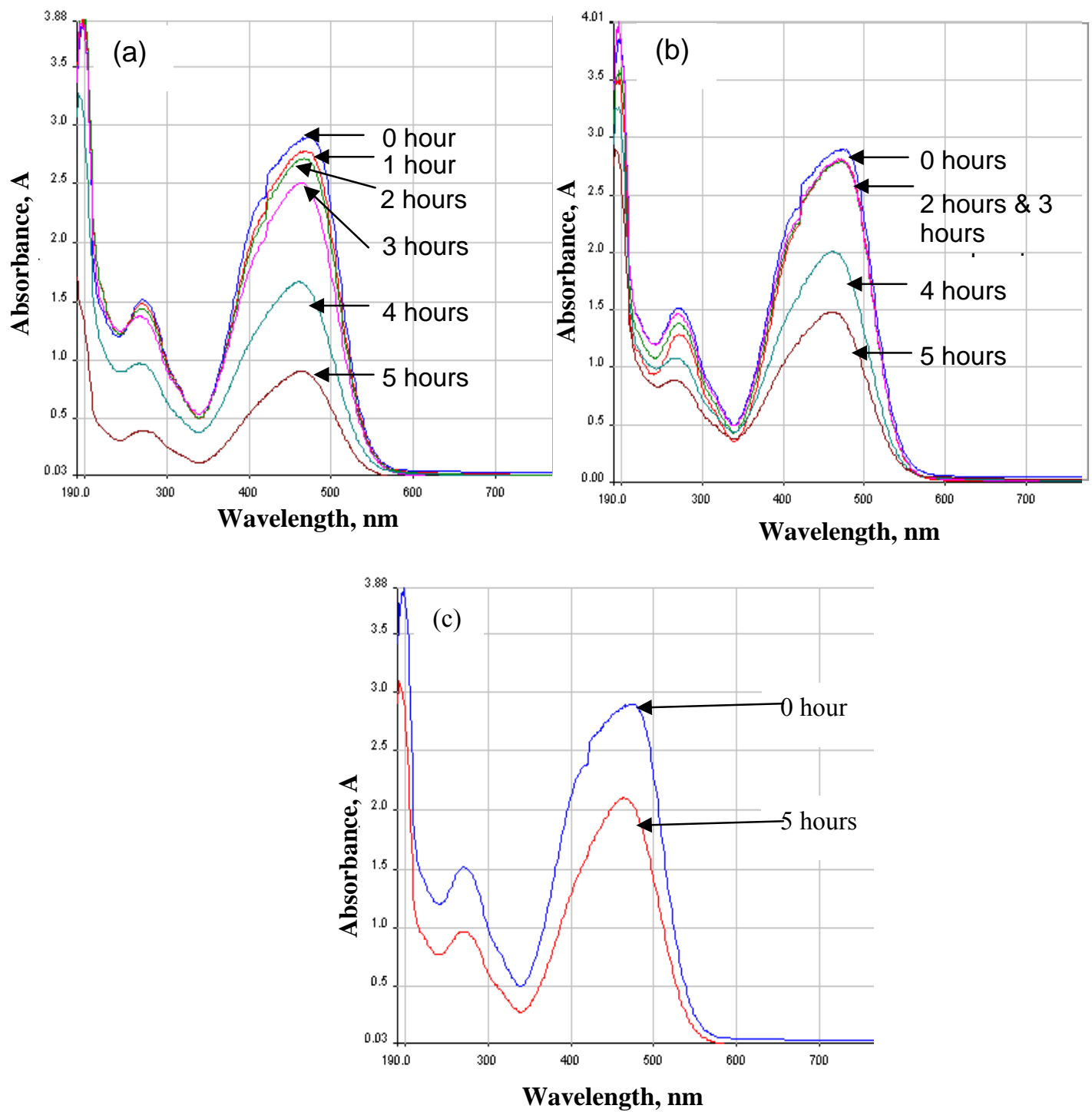

Figure 7: Analysis of absorbance of methylene orange undergo photocatalytic testing with (a) in-situ carbon doped $\mathrm{TiO}_{2}$ (b) ex-situ carbon doped $\mathrm{TiO}_{2}$ and (c) pure $\mathrm{TiO}_{2}$ 


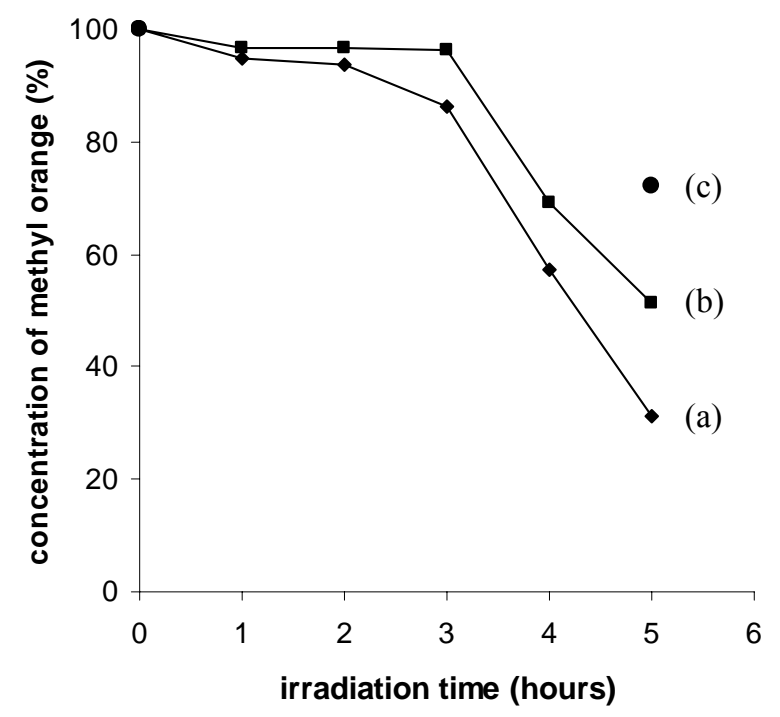

Figure 8: Plots of methyl orange concentration versus irradiation time for (a) in-situ, (b) ex-situ doped sample and (c) pure $\mathrm{TiO}_{2}$

\section{CONCLUSION}

In summary, anodization of the $\mathrm{Ti}$ foil at $\mathrm{pH} 4$ resulted in a well organized $\mathrm{TiO}_{2}$ nanotube. Approximately $6.4 \%$ and $5.1 \%$ carbon was incorporated into $\mathrm{TiO}_{2}$ by insitu and ex-situ method, respectively. This result indicates in-situ method is more efficient than ex-situ method to prepare carbon doped $\mathrm{TiO}_{2}$. XRD pattern of the sample annealed at $500{ }^{\circ} \mathrm{C}$ indicated the presence of crystalline anatase and rutile phase. It appears that crystal structure and carbon content are an important factor affecting the photocatalytic activity. In this work, it was found in-situ doped $\mathrm{TiO}_{2}$ with $62 \%$ of anatase and $38 \%$ rutile had degraded the methyl orange by $69 \%$, which is $20 \%$ and 41 $\%$ higher than ex-situ and pure $\mathrm{TiO}_{2}$, respectively.

\section{ACKNOWLEDGEMENT}

The author would like to thank Universiti Sains Malaysia because this work was sponsored through Short Term Grant 2007: 6035227 and FRGS: 6070020

\section{REFERENCES}

[1] M.R. Hoffmann, S.T. Martin, W. Choi, D.W. Bahnemann, Chem. Rev. 95 (1995) 69-96.

[2] A. Fujishima, K. Hashimoto, T. Watanabe, BKC Inc., Tokyo, 1999.

[3] Z. Liu, X. Zhang, S. Nishimoto, T. Mukarami, A. Fujishima, Environ. Sci. Technol. 42 (2008) 8547-8551.

[4] V. S. Saji, H. C. Choe, W. A. Brantley, Acta Biomaterialia, 5 (2009) 2303-2310.

[5] G. K. Mor, M. A. Carvalho, O. K. Varghese, M. V. Pishko, C. A. Grimes, J. Mater. Res, 19 (2004) 628-634.

[6] K. Zhu, T. B, Vinzant, N. R. Neale, A. J. Frank, Nano Letters, 7 (2007) 3739-3746.

[7] K.E. Karakitsou, X.E. Verykios, J. Phys. Chem. 97 (1993) 1184-1189.

[8] W. Choi, A. Termin, M.R. Hoffmann, J. Phys. Chem. 98 (1994) 13669-13679.

[9] H. Yamashita, M. Harada, J. Misaka, M. Takeushi, M. Anpo, J. Photochem. Photobiol. A 148 (2002) $257-261$.

[10] Wang H., Lewis J.P., Journal of physics: Condense Matter Vol. 18 (2006) 421-434.

[11] T. Morikawa, R. Asahi, T. Ohwaki, K. Aoki, Y. Taga, Jpn. J. Appl. Phys., Part 240 (2001) L561-L563.

[12] Y. Aita, M. Komatsu, S. Yin, T. Sato, J. Solid State Chem. 177 (2004) 3235-3238.

[13] R. Asahi, T. Morikawa, T. Ohwaki, K. Aoki, Y. Taga, Science 293 (2001) 269-271.

[14] Y.Wang, C.X. Feng, Z.S. Jin, J.W. Zhang, H.J. Yang, S.L. Zhang, J.Mol. Catal. A: Chem. 260 (2006) 1-3.

[15] S. Sakthivel, H. Kisch, Angew. Chem. Int. Ed. 42 (2003) 4908-4911.

[16] C.S.Kuo,Y.H. Tseng, C.H. Huang,Y.Y. Li, J. Mol. Catal. A: Chem. 270 (2007) 93-100.

[17] J. Lin, R. Zong, M. Zhou, Y. Zhu, Appl. Catal. B: Environ., 89 (2009) 425-431.

[18] T. Umebayashi, T. Yamaki, H. Ito, K. Asahi, Appl. Phys. Lett. 81 (2002) 454-456.

[19] T. Ohno, T. Mitsui, M. Matsumura, Chem. Lett. 32 (2003) 364-365.

[20] J.C. Yu, W.K. Ho, J.G. Yu, H. Yip, P.K.Wong, J.C. Zhao, Environ. Sci. Technol. 39 (2005) 1175-1179.

[21] S. Sreekantan, R. Hazan, Z. Lockman, Thin Solid Film 518 (2009) 16-21

[22] S. Sreekantan, Z. Lockman, R. Hazan, M. Tasbihi, L. K. Tong, A. R. Mohamed, Journal of Alloys and Compounds 485 (2009)478-483

[23] S. Sreekantan, R. Hazan, K. A. Saharudin, I. Mat. MicroSoM (Buletin of the Electron Microscopy Society of Malaysia), 7 (2009) 7-9.

[24] R. Hazan, S. Sreekantan, A. Abdul Khalil, I. M. S. Nordin, I. Mat., Journal of Physical Science, 20 (2009) 35-47.

[25] S. Sreekantan, R. Hazan, Z. Lockman, Synthesis, Solid State Science and Technology, 17 (2009) 132-139. 
[26] N. A. Jani, Z.Lockman, S. Sreekantan, L. Schmidt-Mande, J. Driscoll, International Conference on X-Rays and related Technique in Research and Industries (2008), 58

[27] S. Bakardjieva, J. Subrt, V. Stengl, M. J. Dianez, M. J. Sayagues, Applied Catalysis B: Environmental 58 (2005) 193-202

[28] J. M. Macak, H. Tsuchiya, L. Taveira, S. Aldabergerova, P. Schmuki, Angew. Chem. Int. Ed., 44 (2005) 7463-7465.

[29] H.Habazaki, M.Uozomi, H.Konno, K.shimizu, P.Skeldon, G.E.Thompson, Corrosion Science, vol. 45, pp. (2003)2063-2073

[30] Y.Li, D.S.Hwang, N.H. Lee, S.J.Kim. Chemical Physics Letters 404 (2005) 25-29 